\title{
High frequency of psychopathology in subjects wishing to lose weight: an observational study in Italian subjects
}

\author{
Valentina Martinelli ${ }^{1, *}$, Ottavia Colombo $^{1}$, Cristiano Nichini ${ }^{1}$, Ilaria Repossi ${ }^{1}$, \\ Piergiuseppe Vinai ${ }^{2,3}$ and Anna Tagliabue ${ }^{1}$ \\ 'Department of Health Sciences, Human Nutrition and Eating Disorders Research Centre, University of Pavia, via \\ Bassi 21, 1-27100 Pavia, Italy: ${ }^{2}$ GNOSIS, No Profit Research Group, Cuneo, Italy: ${ }^{3}$ Studi Cognitivi, \\ Postgraduate Psychotherapy School Division, Milan, Italy
}

Submitted 11 March 2010: Accepted 22 April 2010: First published online 11 June 2010

\begin{abstract}
Objective: To investigate the frequency of psychiatric disorders in subjects wishing to lose weight categorized according to BMI.

Design: Cross-sectional study.

Setting: An academic outpatient clinical nutrition service in Italy.

Subjects: A total of 207 subjects (thirty-nine men and 168 women; mean age: $38 \cdot 7$ (SD $14 \cdot 1$ ) years) consecutively attending the study centre for the first time between January 2003 and December 2006.

Results: In the entire study group, eighty-three (40\%) subjects had a psychiatric disorder according to criteria of the Diagnostic and Statistical Manual of Mental Disorders, fourth edition, text revision. Eating disorders were the most prevalent psychiatric condition (thirty-six subjects, $17 \cdot 4 \%$ ), followed by mood and anxiety disorders $(9 \cdot 7 \%$ and $8 \cdot 7 \%$, respectively). The frequency of psychiatric disorders among different BMI categories was as follows: $75 \cdot 0 \%$ in underweight, $50 \cdot 0 \%$ in normal weight, $33 \cdot 3 \%$ in overweight and $33 \cdot 3 \%$ in obese subjects.

Conclusions: Psychiatric disorders may be frequently found in subjects wishing to lose weight. Our results highlight the importance of psychiatric assessment especially in underweight and normal-weight subjects.
\end{abstract}

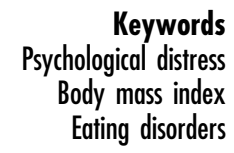

According to the National Institutes of Health (NIH) clinical guidelines on the identification, evaluation and treatment of overweight and obesity in adults, weight loss is recommended for subjects with a BMI of $\geq 30 \mathrm{~kg} / \mathrm{m}^{2}$ and for those with a BMI between 25 and $29.9 \mathrm{~kg} / \mathrm{m}^{2}$ with two or more risk factors ${ }^{(1)}$. However, there is evidence to suggest that the wish to lose weight extends to include normal-weight or underweight subjects, possibly for cultural, social or psychological reasons $^{(2,3)}$. Of note, normal-weight dieters appear to be chiefly heedful of this behaviour through public health messages ${ }^{(3)}$. According to Italy National Statistics Agency (ISTAT) 2002 data, 6.2\% of subjects in a representative sample of the Italian population were dieters, and almost half of them were of normal weight ${ }^{(4)}$. In an ISTAT 2005 report, weekly weight check procedures were more frequent in normal-weight $(28.5 \%)$ than in overweight or obese women $(22 \cdot 5-22 \cdot 7 \%)^{(5)}$.

The reasons why normal-weight subjects try to lose weight are not yet completely defined. A significant relationship between the wish to lose weight, body dissatisfaction and interpersonal distress has been reported ${ }^{(2)}$. Interestingly, dissatisfaction with weight is not limited to young women but has also been reported in middle-aged and elderly women ${ }^{(6)}$.
Earlier studies focusing on the relationship between the wish to lose weight and psychiatric or psychological conditions have mainly been focused on obese subjects ${ }^{(7)}$. Results have generally reported a higher frequency of psychiatric disorders in obese persons wishing to lose weight ${ }^{(8-10)}$. We therefore reasoned that the wish for weight reduction could be driven not only by a health behaviour but also by psychological distress or psychiatric disorders. Whether psychiatric diagnoses could be associated with the wish to lose weight in normal-weight or underweight subjects has not been previously addressed. The aim of the present study was to investigate the frequency of psychiatric diagnosis according to different BMI categories in all consecutive patients presenting to an outpatient clinical nutrition service with the wish to lose weight.

\section{Methods}

The present observational study was cross-sectional in nature. Between January 2003 and December 2006, a total of 329 subjects presented consecutively to the Human Nutrition and Eating Disorders Research Centre, University 
of Pavia, requiring a dietary treatment. The reasons for asking about the diet were assessed through a specific form, including the wish to lose weight (237 patients), the need for a medical nutrition therapy for a specific disease (seventy-six subjects) and nutritional counselling for pregnancy or exercise (sixteen subjects). All subjects wishing to lose weight ( $n$ 237) were deemed to be eligible. Exclusion criteria were: pregnancy, severe physical illnesses (malignancies or severe organ failure) and inability to provide consent. Thirty subjects were unwilling to participate in the study. A total of 207 subjects were therefore included in the final analysis.

Weight and height were measured using standard techniques from which BMI was calculated. Patients were classified into four groups according to BMI: underweight $\left(\mathrm{BMI}<18 \cdot 5 \mathrm{~kg} / \mathrm{m}^{2}\right)$, normal weight $\left(\mathrm{BMI}=18 \cdot 5-24.9 \mathrm{~kg} / \mathrm{m}^{2}\right)$, overweight $\left(\mathrm{BMI}=25-29 \cdot 9 \mathrm{~kg} / \mathrm{m}^{2}\right)$ and obese $(\mathrm{BMI} \geq$ $\left.30 \mathrm{~kg} / \mathrm{m}^{2}\right)^{(11)}$. Diagnosis of Axis I and II psychiatric disorders was made by a board-certified psychiatrist according to criteria of the Diagnostic and Statistical Manual of Mental Disorders, fourth edition, text revision (DSM-IV-TR) ${ }^{(12)}$. The study procedures complied with the tenets of the Helsinki Declaration and the Institutional Review Board of the University of Pavia approved the protocol. All subjects gave their written informed consent. The main objective was to assess the frequency of psychiatric disorders in subjects wishing to lose weight across different BMI categories. Continuous data are presented as means and standard deviations and were compared across the study groups by using one-way ANOVA or the Student's $t$ test, as appropriate. Categorical variables are shown as counts and percentages and compared across groups by using the $\chi^{2}$ analysis. All computations were performed with the Statistical Package for Social Sciences statistical software package version $15 \cdot 0$
(SPSS Inc., Chicago, IL, USA). Two-tailed $P$ values $<0 \cdot 05$ were deemed to be statistically significant.

\section{Results}

The sociodemographic characteristics of the study patients according to different BMI categories are depicted in Table 1. A total of 207 subjects (thirty-nine men and 168 women, mean age: $38 \cdot 7$ (SD $14 \cdot 1)$ years) were included in the present study. In the entire study sample, the mean BMI was 28.5 (SD 6.6$) \mathrm{kg} / \mathrm{m}^{2}$. There were significant differences in marital and employment status according to BMI categories. No other significant differences were found.

In the entire study group, eighty-three (40\%) subjects had a psychiatric disorder according to DSM-IV-TR criteria. The frequency of psychiatric diagnosis was significantly higher in women (44\%, seventy-four subjects) than in men $(23 \cdot 1 \%$, nine subjects; $P<0 \cdot 05)$. Eating disorders were the most prevalent psychiatric disorders ( $n$ 36, 17·4\%), followed by mood disorders ( $n 20,9 \cdot 7 \%$ ) and anxiety disorders ( $n$ 18, $8.7 \%$ ). Only women were affected by eating disorders, and the distribution of the diagnosis was as follows: anorexia nervosa (AN) in seven patients $(3 \cdot 4 \%)$, bulimia nervosa $(\mathrm{BN})$ in ten $(4 \cdot 8 \%)$, binge eating disorder (BED) in nine $(4 \cdot 3 \%)$ and other eating disorders not otherwise specified (EDNOS other than BED) in ten $(4 \cdot 8 \%)$ subjects. In patients with ED, there were nine who also met the criteria for a diagnosis in another major diagnostic category (four major depression, two anxiety disorders and three personality disorders plus major depression). Mood disorders (six cases, 15.4\%) and anxiety disorders (three cases, $7 \cdot 7 \%$ ) were the only two diagnostic categories in men.

Table 1 Sociodemographic characteristics of the study patients

\begin{tabular}{|c|c|c|c|c|c|c|c|c|c|}
\hline \multirow[b]{2}{*}{ Variables } & \multicolumn{2}{|c|}{ Underweight } & \multicolumn{2}{|c|}{ Normal weight } & \multicolumn{2}{|c|}{ Overweight } & \multicolumn{2}{|c|}{ Obese } & \multirow[b]{2}{*}{$P^{*}$} \\
\hline & Mean & $\mathrm{SD}$ & Mean & SD & Mean & $\mathrm{SD}$ & Mean & $\mathrm{SD}$ & \\
\hline \multirow[t]{2}{*}{ Age (years) } & $27 \cdot 5$ & $7 \cdot 6$ & $32 \cdot 6$ & $12 \cdot 3$ & $38 \cdot 8$ & $13 \cdot 3$ & $44 \cdot 1$ & 14 & $<0.05$ \\
\hline & $n$ & $\%$ & $n$ & $\%$ & $n$ & $\%$ & $n$ & $\%$ & \\
\hline \multicolumn{10}{|l|}{ Gender } \\
\hline Female & 15 & $93 \cdot 8$ & 40 & $90 \cdot 9$ & 49 & $74 \cdot 2$ & 64 & $79 \cdot 0$ & 0.08 \\
\hline Total & 16 & $7 \cdot 7$ & 44 & $21 \cdot 3$ & 66 & $31 \cdot 9$ & 81 & $39 \cdot 1$ & \\
\hline \multicolumn{10}{|l|}{ Education (years) } \\
\hline $0-8$ & 3 & $18 \cdot 8$ & 9 & $20 \cdot 5$ & 19 & $28 \cdot 8$ & 24 & $29 \cdot 6$ & 0.56 \\
\hline $9-13$ & 10 & $62 \cdot 5$ & 26 & $59 \cdot 1$ & 33 & $50 \cdot 0$ & 48 & $59 \cdot 3$ & \\
\hline$>13$ & 3 & $18 \cdot 8$ & 9 & $20 \cdot 5$ & 14 & $21 \cdot 2$ & 9 & $11 \cdot 1$ & \\
\hline \multicolumn{10}{|l|}{ Marital status } \\
\hline Married or living with a partner & 5 & $31 \cdot 2$ & 15 & $34 \cdot 1$ & 44 & $66 \cdot 7$ & 58 & $71 \cdot 6$ & $<0.05$ \\
\hline Separated, divorced or widowed & 0 & - & 0 & - & 3 & $4 \cdot 5$ & 6 & $7 \cdot 4$ & \\
\hline Single & 11 & $68 \cdot 8$ & 29 & $65 \cdot 9$ & 19 & $28 \cdot 8$ & 17 & $21 \cdot 0$ & \\
\hline \multicolumn{10}{|l|}{ Employment } \\
\hline Student & 8 & $50 \cdot 0$ & 15 & $34 \cdot 0$ & 11 & $16 \cdot 7$ & 3 & $3 \cdot 7$ & $<0.05$ \\
\hline Unemployed/retired & 0 & $0 \cdot 0$ & 4 & $9 \cdot 1$ & 5 & $6 \cdot 7$ & 7 & $8 \cdot 6$ & \\
\hline Employed & 6 & $37 \cdot 5$ & 22 & $50 \cdot 0$ & 43 & $65 \cdot 2$ & 55 & $67 \cdot 9$ & \\
\hline Homemaker & 2 & $12 \cdot 5$ & 3 & $6 \cdot 8$ & 6 & $9 \cdot 1$ & 14 & $17 \cdot 3$ & \\
\hline
\end{tabular}

*One-way ANOVA test for continuous variables and $\chi^{2}$ test for categorical variables across the four BMI classes. 
Table 2 Frequency of psychiatric diagnosis across different BMI classes

\begin{tabular}{|c|c|c|c|c|c|c|c|c|c|c|}
\hline \multirow[b]{2}{*}{ Psychiatric diagnosis } & \multicolumn{2}{|c|}{ Underweight ( $n$ 16) } & \multicolumn{2}{|c|}{ Normal weight ( $n$ 44) } & \multicolumn{2}{|c|}{ Overweight ( $n$ 66) } & \multicolumn{2}{|c|}{ Obese $(n 81)$} & \multicolumn{2}{|c|}{ Total ( $n$ 207) } \\
\hline & $n$ & $\%$ & $n$ & $\%$ & $n$ & $\%$ & $n$ & $\%$ & $n$ & $\%$ \\
\hline \multicolumn{11}{|l|}{ Present } \\
\hline Substance-related disorders & 0 & - & 0 & - & 0 & - & 1 & $1 \cdot 2$ & 1 & 0.05 \\
\hline Anxiety disorders & 1 & $6 \cdot 2$ & 3 & $6 \cdot 8$ & 5 & $7 \cdot 6$ & 9 & $11 \cdot 1$ & 18 & $8 \cdot 70$ \\
\hline Sleep disorders & 0 & - & 0 & - & 0 & - & 1 & $1 \cdot 2$ & 1 & 0.05 \\
\hline Eating disorders & 11 & $68 \cdot 8$ & 11 & $25 \cdot 0$ & 6 & $9 \cdot 0$ & 8 & $9 \cdot 9$ & 36 & $17 \cdot 40$ \\
\hline Mood disorders & 0 & - & 4 & $9 \cdot 1$ & 10 & $15 \cdot 2$ & 6 & $7 \cdot 4$ & 20 & $9 \cdot 70$ \\
\hline Personality disorders & 0 & - & 3 & $6 \cdot 8$ & 1 & 1.5 & 1 & $1 \cdot 2$ & 5 & $2 \cdot 40$ \\
\hline $\begin{array}{l}\text { Psychiatric disorders due to } \\
\text { general medical conditions }\end{array}$ & 0 & - & 0 & - & 0 & - & 1 & $1 \cdot 2$ & 1 & 0.05 \\
\hline $\begin{array}{l}\text { Schizophrenia and other } \\
\text { psychotic disorders }\end{array}$ & 0 & - & 1 & $2 \cdot 3$ & 0 & - & 0 & - & 1 & 0.05 \\
\hline None & 4 & $25 \cdot 0$ & 22 & $50 \cdot 0$ & 44 & $66 \cdot 7$ & 54 & $66 \cdot 7$ & 124 & $60 \cdot 00$ \\
\hline
\end{tabular}

$P<0.05, \chi^{2}$ test across different BMI categories.

The frequency of psychiatric disorders decreased significantly with increasing BMI categories $(P<0 \cdot 05$; Table 2$)$. The frequency of psychiatric disorders among underweight subjects was $75 \cdot 0 \%$. In particular, $68 \cdot 8 \%$ of them had a diagnosis of eating disorders (43.8\% $\mathrm{AN}, 6 \cdot 2 \% \mathrm{BN}$ and $18 \cdot 8 \%$ EDNOS other than BED) and $6 \cdot 2 \%$ had anxiety disorders. The frequency of psychiatric disorders in normalweight subjects was $50 \%$. Of note, $25 \%$ of normal-weight subjects had a diagnosis of eating disorders $(13.6 \% \mathrm{BN}$, $9 \%$ EDNOS other than BED and $2 \cdot 3 \%$ BED). The frequency of psychiatric disorders among overweight subjects was $33 \cdot 3 \%$. The frequency of eating, mood, anxiety and personality disorders in the overweight group was $9 \cdot 0 \%$, $15 \cdot 2 \%, 7 \cdot 6 \%$ and $1.5 \%$, respectively. Among subjects affected by eating disorders, $4 \cdot 5 \%$ were diagnosed with BN and $4.5 \%$ with BED. The frequency of psychiatric disorders in obese subjects was $33 \cdot 3 \%$. The most prevalent psychiatric disturbances were anxiety disorders $(11 \cdot 1 \%)$, eating disorders $(9 \cdot 9 \%)$ and mood disorders $(7 \cdot 4 \%)$. Among subjects affected by eating disorders, $6 \cdot 2 \%$ suffered from BED and $3 \cdot 7 \%$ from EDNOS other than BED.

\section{Discussion}

In the present study, we found a significant proportion of normal-weight and underweight subjects who were wishing to lose weight (29\% of the entire study sample). This finding is in keeping with previous preliminary observations ${ }^{(2,3)}$. The wish to lose weight in normal-weight subjects has been mainly reported in young women who appeared to be heedful of this behaviour by socio-cultural pressure $^{(2,13)}$. However, the question as to whether the wish to lose weight may be related to the presence of overt psychiatric disorders remains to be established.

The main finding in the present study is the significant prevalence of psychiatric disorders ( $40 \%)$ in subjects who were wishing to lose weight, especially in underweight and normal-weight subjects. This was mainly driven by the prevalence of eating disorders, followed by mood and anxiety disorders. It has been recently shown that sociodemographic data such as gender, educational factors, marital or employment status may influence the prevalence of psychiatric disorders ${ }^{(14)}$. In our study, however, we found no significant association between sociodemographic characteristics and the frequency of psychiatric conditions. In addition, the study of De Girolamo et al. ${ }^{(14)}$ did not address the distribution of psychiatric diagnoses according to different BMI categories. The relationship between BMI and mental health has been investigated in the European Study on the Epidemiology of Mental Disorders (ESEMeD) ${ }^{(15)}$, which included the ISTAT findings in the Italian population. In keeping with other reports ${ }^{(8-10)}$, the ESEMeD study found that obese subjects were $30-40 \%$ more likely to suffer from one or more mental disorders compared with normalweight subjects ${ }^{(15)}$. Although we have excellent epidemiological data on the prevalence of mental disorders in obese subjects $^{(16-18)}$ and in the general population ${ }^{(14)}$, less is known about outpatient populations and the distribution of psychiatric diagnosis according to DSM-IV-TR criteria ${ }^{(12)}$ in normal-weight and underweight subjects who wish to lose weight. Ricca et $a l^{(18)}$ reported that obese patients seeking weight-loss treatment had a higher prevalence of depressive symptoms than normal-weight controls who were not weight preoccupied. The present study highlights the need for careful psychiatric assessment of underweight or normal-weight subjects wishing to lose weight. The results of our study should be interpreted within the context of its limitations. First, our sample is representative of consecutive patients attending an academic outpatient clinical nutrition service in Italy and thus may not be representative of the entire population wishing to lose weight. Second, our study was cross-sectional in nature and no inference can be drawn on the causal relationship between weight control and mental health. Third, we did not conduct a structured psychiatric clinical interview with normal-weight controls who were not weight preoccupied. We have therefore interpreted our findings in the framework of currently available epidemiological data, with special reference to Italy. These limitations 
notwithstanding, our study also has some strengths. Psychiatric interviews were administered not only in obese patients but also in all subjects who were wishing to lose weight. In addition, all subjects presented spontaneously to our centre and volunteer bias can be reasonably excluded. The psychiatric interview was also administered as part of our standard diagnostic protocol.

There are two main results of our study that deserve consideration. First, the wish to lose weight is not limited to obese or overweight subjects. Second, normal-weight and underweight subjects wishing to lose weight show a significant prevalence of psychiatric disorders. This clearly warrants the need to increase awareness of psychiatric conditions not only in obese but also in normal-weight or underweight subjects who are weight preoccupied.

\section{Acknowledgements}

The present study received no specific funding from any agency in the public, commercial or not-for-profit sectors. The authors have no conflict of interest to disclose. V.M. and O.C. contributed to data analysis and writing of the manuscript; C.N., I.R. and P.V. participated in the data collection and interpretation; A.T. was responsible for overall scientific direction and supervision.

\section{References}

1. NHLBI Obesity Education Initiative Expert Panel on the Identification, Evaluation, and Treatment of Overweight and Obesity in Adults (1998) Clinical guidelines on the identification, evaluation, and treatment of overweight and obesity in adults - the evidence report. National Institutes of Health. Obes Res 6, 51S-209S.

2. Boschi V, Bellini O, Matrone G et al. (2006) Why do normal weight young women look for diet therapy? Findings from a pilot study in a clinical and non-clinical population. Eat Weight Disord 12, e35-e38.

3. Biener L \& Heaton A (1995) Women dieters of normal weight: their motives, goals and risks. Am J Public Health 85, 714-717.

4. Italy National Institute of Statistics (ISTAT) (2002) Fattori di rischio e tutela della salute. Indagine multiscopo sulle famiglie 'Condizione di salute e ricorso ai servizi sanitari'
Anni 1999-2000. ISTAT Collana Informazioni no. 12. Rome: ISTAT Press.

5. Italy National Institute of Statistics (ISTAT) (2005) Stili di vita e condizioni di salute. Indagine multiscopo sulle famiglie 'Aspetti della vita quotidiana' Anno 2003. ISTAT Collana Informazioni no. 25. Rome: ISTAT Press.

6. Allaz AF, Bernstein M, Rouget P et al. (1998) Body weight preoccupation in middle-age and ageing women: a general population survey. Int J Eat Disord 23, 287-294.

7. Simon GE, Von Korff M, Saunders K et al. (2006) Association between obesity and psychiatric disorders in the US adult population. Arch Gen Psychiatry 63, 1-7.

8. Marchesini G, Bellini M, Natale S et al. (2003) Psychiatric distress and health-related quality of life in obesity. Diabetes Nutr Metab 16, 145-154.

9. Onyike CU, Crum RM, Lee HB et al. (2003) Is obesity associated with major depression? Results from the Third National Health and Nutrition Examination Survey. Am J Epidemiol 158, 1139-1147.

10. Scott KM, Bruffaerts R, Simon GE et al. (2008) Obesity and mental disorders in the general population: results from the world mental health surveys. Int J Obes 32, 192-200.

11. National Task Force on the Prevention and Treatment of Obesity (2000) Dieting and the development of eating disorders in overweight and obese adults. Arch Intern Med 160, 2581-2589.

12. American Psychiatric Association (2000) Diagnostic and Statistical Manual of Mental Disorders, 4th ed., Text Revision (DSM-IV-TR). Washington, DC: American Psychiatric Press.

13. Gowers SG \& Shore A (2001) Development 219 of weight and shape concerns in the aetiology of eating disorders. Br J Psychiatry 179, 236-242.

14. De Girolamo G, Polidori G, Morosini P et al. (2006) Prevalence of common mental disorders in Italy: results from the European Study of the Epidemiology of Mental Disorders (ESEMeD). Soc Psychiatry Psychiatr Epidemiol 41, 853-861.

15. Bruffaerts R, Demyttenaere K, Vilagut G et al. (2008) The relationship between body mass index, mental health, and functional disability: a European population perspective. Can J Psychiatry 53, 679-688.

16. Goldstein LT, Goldsmith SJ, Anger K et al. (1996) Psychiatric symptoms in clients presenting for commercial weight reduction treatment. Int J Eat Disord 20, 191-197.

17. Goldsmith SJ, Anger-Friedfeld K, Beren S et al. (1992) Psychiatric illness in patients presenting for obesity treatment. Int J Eat Disord 12, 63-71.

18. Ricca V, Mannucci E, Di Bernardo M et al. (1996) Psychopathological and clinical features among the ambulatory population of obese patients. Minerva Psichiatr 37, $53-58$. 